\title{
National Survey on Training in Pediatric Cardiology by the "Junges Forum" of the DGPK
}

\author{
Jan-Pit Horst ${ }^{1}$ Miriam Michel ${ }^{2}$ Rouven Kubicki ${ }^{3}$ Nora Lang ${ }^{4}$ Martin Zschirnt ${ }^{5}$ Julia Moosmann ${ }^{6}$
}

\footnotetext{
${ }^{1}$ Center of Congenital Heart Disease, Heart and Diabetes Center Northrhine-Westfalia, Ruhr-University of Bochum, Bad Oeynhausen, Germany

2 Division of Pediatric Cardiology, Department of Pediatrics III, Medical University of Innsbruck, Innsbruck, Tirol, Austria

3 University Heart Center Freiburg - Bad Krozingen, Department of Congenital Heart Disease and Pediatric Cardiology, Medical Center University of Freiburg, Faculty of Medicine, Freiburg, Germany

${ }^{4}$ Department of Paediatric Cardiology and Congenital Heart Disease, German Heart Centre, Munich, Germany

${ }^{5}$ Department of Pediatric Cardiology, University Hospital of Giessen and Marburg Campus Giessen, Giessen, Hessen, Germany

${ }^{6}$ Department of Pediatric Cardiology, Friedrich-Alexander University Erlangen-Nuremberg, Erlangen, Bavaria, Germany
}

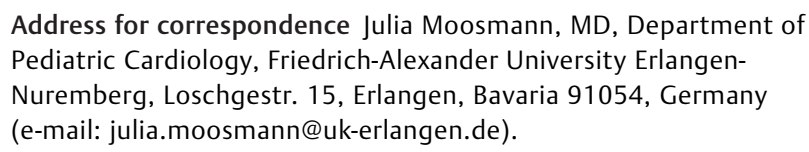

Address for correspondence Julia Moosmann, MD, Department of Pediatric Cardiology, Friedrich-Alexander University ErlangenNuremberg, Loschgestr. 15, Erlangen, Bavaria 91054, Germany (e-mail: julia.moosmann@uk-erlangen.de).

Thorac Cardiovasc Surg 2020;68:e1-e8.

\begin{abstract}
Keywords

- congenital heart disease

- CHD

- cardiology/ cardiologist

- pediatric

Background This is the first national survey of residents and fellows in pediatric cardiology in Germany evaluating training, research activity, and the general working environment.

Methods An online questionnaire including 62 questions (SurveyMonkey) was developed by the "Junges Forum" of the German Society of Pediatric Cardiology. Fellows and residents during training and up to 3 years after completing their pediatric cardiology fellowship were invited to participate.

Results A total of 102 pediatric cardiology fellows and residents completed the questionnaire. Many participants complained about their training as being unstructured $(47 \%)$ and non-transparent (37\%). The numbers of technical and catheter interventions required by the national medical board in Germany cannot be achieved, especially regarding invasive procedures. Sixty per cent work more than contractually agreed, usually in Germany it is 40 hours daytime work plus on calls, while $90 \%$ of all participants prefer less than 50 weekly working hours; $50 \%$ of the participants are engaged in research that is usually done during their spare time. More than $90 \%$ are satisfied with their professional relationships with colleagues and coworkers. Seventyeight per cent describe their career perspectives as promising, and $84 \%$ would start a fellowship in pediatric cardiology again.

Conclusion The majority of pediatric cardiology fellows and residents are satisfied with their working environment and with their choice of a career in pediatric cardiology. Besides the heavy work load, we identified the urgent desire for better structured transparent clinical training concept including the teaching of manual skills, i.e., invasive procedures and catheterization.
\end{abstract}

received

July 7, 2019

accepted after revision

December 5, 2019
DOI https://doi.org/

10.1055/s-0039-1700968. ISSN 0171-6425. (c) 2020 Georg Thieme Verlag KG
Stuttgart · New York

License terms

(c) (1) $\ominus$ (\$) 


\section{Introduction}

The "Junges Forum" of the German Society of Pediatric Cardiology (DGPK), founded in 2015, represents the interests of residents and fellows in pediatric cardiology training in close cooperation with the DGPK. The "Junges Forum" discusses aspects of clinical education and training, science, and research. National and international collaborations with junior members of other societies in the field of cardiovascular medicine are being promoted. Decision making in congenital heart disease (CHD) requires highly qualified specialists with great compassion for their work. In Germany, there are 22 pediatric cardiology centers performing surgery for CHD and 35 centers providing congenital cardiac catheterization. ${ }^{1}$ Approximately 200 residents/fellows are currently undergoing pediatric cardiology training defined and regulated by the education guidelines of the national and state medical board in Germany. To become a pediatric cardiologist, fellows must undergo training for least 5 years in general pediatric and adolescent medicine and 3 additional years in pediatric cardiology. These 3 years are considered as cardiology core fellowship training program (general pediatric cardiology). The training can be completed at one of the university heart centers, general pediatric hospitals under the supervision of a pediatric cardiologist, in pediatric outpatient departments or private clinics. A maximum of 18 months can be completed in the outpatient area according to the regulations of the national medical board. During pediatric cardiology training, fellows must acquire key cardiology competence in diagnosing and treating congenital cardiovascular diseases. Besides the rapidly advancing diagnostic and technical skills, fellows also need to acquire specific manual skills. Optional are activities in political offices (e.g., active participation in a working group or "Junges Forum" of the DGPK), teaching, and research projects.

We conducted this first national survey in Germany to evaluate the training in pediatric cardiology and assess the attitude among young residents and the difficulty of balancing the act between clinical and scientific work as well as family life among young residents and fellows.

\section{Materials and Methods}

The online questionnaire was developed by the "Junges Forum" of the DGPK comprising questions of sociodemographic data, structure of the training, research activity, and the working environment. Pediatric cardiology fellows and residents during training and up to 3 years after completion of their pediatric cardiology fellowship in Germany were invited to participate. The access information was sent to all institutions authorized to train in pediatric cardiology in Germany and all members of the "Junges Forum" of the DGPK via e-mail. A reminder was sent after 4 weeks.

The questionnaire included 62 questions with multiple choice $(n=34)$ or nominal Likert scales $(n=23)$ and five questions requiring free answers in comment fields.

The questionnaire could be filled out anonymously on the web-based online-platform SurveyMonkey (SurveyMonkey, San Mateo, California, United States) from September 2017 to
May 2018. Statistical analysis was performed using Microsoft Excel (Microsoft Corporation, Redmond, Washington, United States). The original and a translated version of the questionnaire are provided as - Supplementary Material.

\section{Results}

\section{Demographic Data}

A total of 102 pediatric cardiology residents and fellows had completed the online questionnaire. We received answers from fellows of all German pediatric cardiology centers. Demographic and work-related data are presented in -Table 1. About $72.5 \%$ of all participants are enrolled in a fellowship program for pediatric cardiology, 11.8\% had completed their specialization in pediatric cardiology, 6.9\% were working as a consultant, and the remaining $8.8 \%$ as other (e.g., resident in general pediatrics).

\section{Pediatric Cardiology Training and Clinical Work}

About $90 \%$ of the participants were satisfied or very satisfied with their working environment and their professional relationships to colleagues and coworkers (-Fig. 1). Pediatric cardiology fellows experience an extremely variable concept of education (-Fig. 2). Despite legally required by the medical board, a written educational concept was not available for 85.3\%; adherence to such a concept was guaranteed in $24.7 \%$ among those remaining. Educational meetings with the program director (mandatory at least once a year) took place for 63.7\%. Eighty-two per cent confirm that regular in-house training courses are performed. Further, training is expected by the employer in addition to regular working hours (79.8\%). Active participation at conferences is expected from $74.0 \%$ of all participants, while $97.8 \%$ are entitled to (paid) leave from work. Participation fees for external meetings and conferences were paid in 50.0\%; $85.9 \%$ had already attended the DGPK annual meeting, 43.6\% international conferences, 53.9\% a course offered by the "DGPK Academy," and 14.1\% the Autumn School of the "Junges Forum" of the DGPK.

Many participants complained of insufficient practical training: In particular, the number of transesophageal echocardiography (TEE), cardiopulmonary exercise testing, and right and left heart catheterization numbers, as required by the national medical board is not achievable within the allotted 3 years ( - Fig. 3 ). Examples of their reasons provided in a free-text comment field were: "structured training missing, structured rotation missing," "mostly working on the intensive care unit (ICU)-not in the outpatient clinic," "very complex patients, consultant performing the procedure," or "pediatric cardiology consultant performing the procedure."

Suggestions on how to improve pediatric cardiology training were: $78.1 \%$ want a reliable rotational system setup, $69.8 \%$ would prefer to pass on paramedical work (e.g., documentation, blood samples) to allied health workers, $68.7 \%$ favor a tutoring system, $40.6 \%$ want further external education options (e.g., by the "Junges Forum" of the DGPK), and 33.3\%, desire an external objective quality assessment for the fellowship programs at each pediatric cardiology center. Furthermore, we received seven free-text comments indicating the desire for "hands-on 
Table 1 Demographic and work-related data of the participants

\begin{tabular}{|c|c|c|c|}
\hline Demographic data & $N$ & $\%$ & n.a. $(n)$ \\
\hline Participants $(n)$ & 102 & & \\
\hline Female & 55 & 54.5 & \multirow[t]{2}{*}{1} \\
\hline Male & 46 & 45.5 & \\
\hline \multicolumn{4}{|l|}{ Age $(y)$} \\
\hline$<30$ & 6 & 5.9 & \multirow[t]{3}{*}{1} \\
\hline $30-39$ & 79 & 78.2 & \\
\hline$>40$ & 16 & 15.9 & \\
\hline Partnership/married & 81 & 81.8 & 3 \\
\hline No children & 57 & 60.0 & \multirow[t]{2}{*}{7} \\
\hline Having $\geq 1$ child & 38 & 40.0 & \\
\hline \multicolumn{4}{|l|}{ Nationality } \\
\hline Germany & 89 & 89.0 & \multirow[t]{3}{*}{2} \\
\hline European country & 6 & 6.0 & \\
\hline Non-European country & 4 & 4.0 & \\
\hline \multicolumn{4}{|l|}{ Medical school } \\
\hline Germany & 91 & 89.2 & \multirow[t]{3}{*}{0} \\
\hline European country & 7 & 6.9 & \\
\hline Non-European country & 4 & 3.9 & \\
\hline \multicolumn{4}{|l|}{ Institution } \\
\hline University clinic & 87 & 85.3 & \multirow[t]{6}{*}{0} \\
\hline Public & 6 & 5.9 & \\
\hline Public (ecclesiastical institution) & 3 & 2.9 & \\
\hline Private & 2 & 2.0 & \\
\hline Outpatient private practice & None & None & \\
\hline Other & 4 & 3.9 & \\
\hline \multicolumn{4}{|l|}{ Certified training institution } \\
\hline $\begin{array}{l}\text { Full pediatric cardiology } \\
\text { training }(3 \mathrm{y})\end{array}$ & 99 & 97.1 & \multirow[t]{2}{*}{0} \\
\hline Less than $3 \mathrm{y}$ & 3 & 2.9 & \\
\hline \multicolumn{4}{|l|}{ Contract duration } \\
\hline Permanent & 16 & 15.8 & \multirow[t]{2}{*}{1} \\
\hline Temporary & 85 & 84.2 & \\
\hline \multicolumn{4}{|l|}{ Position } \\
\hline Fellow pediatric cardiology & 74 & 72.5 & \multirow[t]{4}{*}{0} \\
\hline Pediatric cardiologist & 12 & 11.8 & \\
\hline Consultant & 7 & 6.9 & \\
\hline Other & 9 & 8.8 & \\
\hline Membership DGPK & 46 & 46.0 & 2 \\
\hline $\begin{array}{l}\text { Membership Junges } \\
\text { Forum DGPK (\%) }\end{array}$ & 26 & 26.0 & 2 \\
\hline
\end{tabular}

Abbreviations: DGPK, German Society of Pediatric Cardiology; n.a., not answered.

Note: Percentages reflect the number of responses.

bedside teaching during routine clinical work including timely feedback" and "more medical staff."

About $31.3 \%$ of all participants would be willing to change their location for a faster and more comprehensive training program; $25.5 \%$ have already changed their institution once and $7.8 \%$ twice to undergo pediatric cardiology training.

Regarding personal interests in specialties, fellows prefer general pediatric cardiology (75.0\%) and cardiac intensive care (67.0\%), followed by imaging (45.0\%) and interventional pediatric cardiology (42.0\%) (-Table 2). To plan their personal future, most participants would prefer working at a specialized center for pediatric cardiology (70.0\%) or as pediatric cardiology consultant in a general pediatric hospital (40.0\%). Being self-employed in a private practice was considered by $42.0 \%$; $15.0 \%$ are planning to work in research, $3.0 \%$ in a rehabilitation clinic, and $1 \%$ in economics and industry.

\section{Research}

A total of $75.8 \%$ of participants have completed or plan to write a doctoral thesis and $30.3 \%$ are striving for a postdoctoral lecturer qualification. Only $10.1 \%$ have no academic title. Fifty per cent of all participants are engaged in research projects. Research is performed by $19.3 \%$ during working hours, but by $71.0 \%$ during their free time. Fellows working on research projects spend a mean $6.9 \pm 6.4$ hours on scientific work per week; $28.4 \%$ have worked independently on a research project, while $24.5 \%$ have applied for a scientific grant; $12.7 \%$ have done research abroad. Regarding publications in a peer-reviewed journal, $37.3 \%$ could claim at least one first authorship and $48.0 \%$ at least one co-authorship.

\section{Work-Life Balance}

The contractually agreed weekly working hours were 42 hours (62\%), 40 hours (17\%), and beyond (maximum 44 hours) or less (minimum 21 hours) (21\%). According to German collective agreements, the weekly working time can be exceeded up to 58 hours, if a physician performs on-call duties in addition to the normal working time and has agreed to an individual optout. However, by German law, the maximum average weekly working time is limited to 48 hours. More than $60 \%$ of the participants worked more than 50 hours per week, $10 \%$ more than 60 hours, while $90 \%$ would prefer a weekly working schedule of less than 50 hours (-Fig. 4). The appeal of pediatric cardiology fellowships is compromised by an unfavorable work-life balance, the current education system, and heavy workload including many working hours beyond the contractually agreed time. Seventy-eight per cent describe promising future perspectives and 69\% encouraging career opportunities (-Fig. 5). Moreover, 84\% would begin a fellowship in pediatric cardiology again.

\section{Discussion}

\section{Pediatric Cardiology Training-Need for More Structured and Improved Teaching of Manual Skills}

Training in pediatric cardiology is competitive; the demand for clinical patient care is high, as is the need for a broad range of technical knowledge including manual skills.

This survey revealed a mismatch between the requirements of national medical board to become a pediatric cardiologist and the teaching opportunities in the daily routine. 


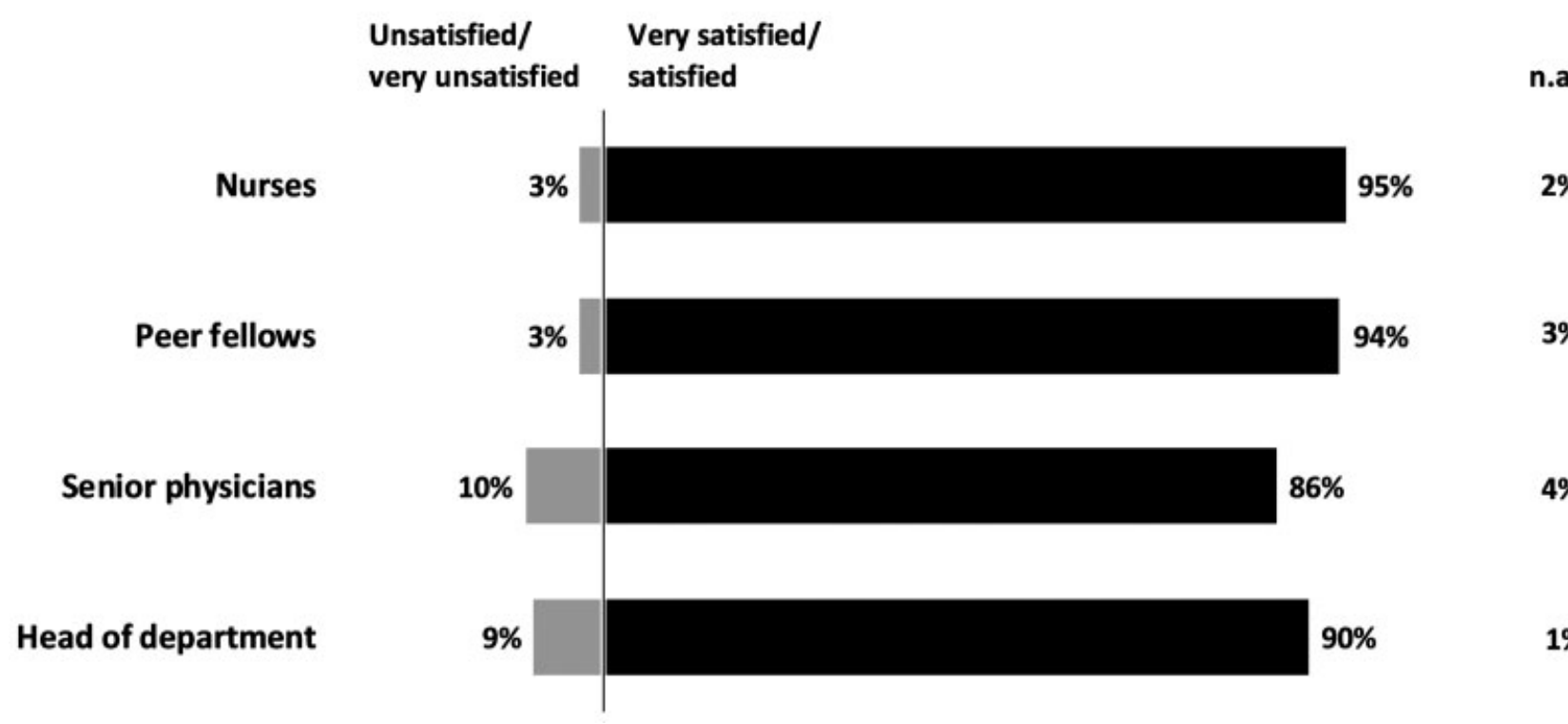

Fig. 1 Participants' professional relationships with colleagues and coworkers. Percentages reflect the number of responses $(n=101)$.

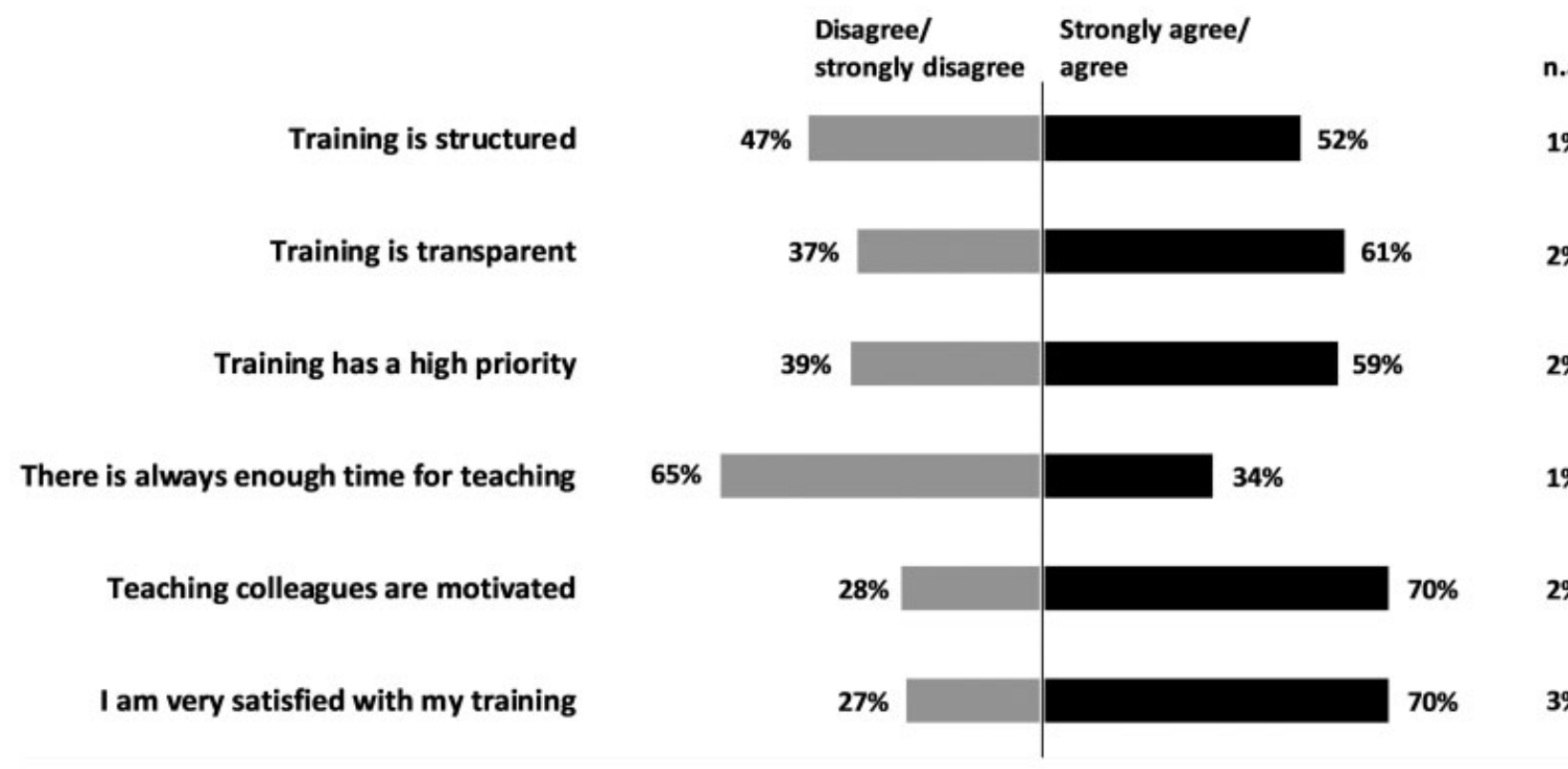

n.a.

$1 \%$

Fig. 2 Participants' opinion of pediatric cardiology training. Percentages reflect the number of responses $(n=101)$.

There are several hurdles to overcome, which are not specific for pediatric cardiology training, including the problems associated with a heavy bureaucratic workload (documentation, administration, and organization) rather than time for bedside teaching sessions. ${ }^{2}$

We also noticed specific problems concerning how interventions, and the manual dexterity they require, are learned. Current as well as future pediatric cardiologists do not just want to "look and learn"-they want and need to be taught "how" things are done according to the traditional teaching method "see one, do one, teach one"; after observing a particular procedure, trainees are expected to be capable of performing that procedure (under supervision). Although some patients are very sick, it is important that trainees be given the supervised opportunity to carry out such inter- ventions and that they not be the sole preserved for experienced interventionalists (e.g., consultant).

To gain the necessary cardiovascular knowledge, we observed the need for thorough structured training including an obligatory or at least reliable rotational system. The curricular content for pediatric cardiology training defined by the national medical board should be adapted to the existing conditions at each teaching institution and should be available as a logbook or clinical guide for all fellows at each training center; however, an external objective evaluation is mandatory. New concepts could be established resembling those at the Boston Children's Hospital and Stanford University, where pediatric cardiology trainees undergo a 4-week "Pediatric Cardiology Fellowship Boot Camp (PCBC)" providing incoming fellows with intensive 


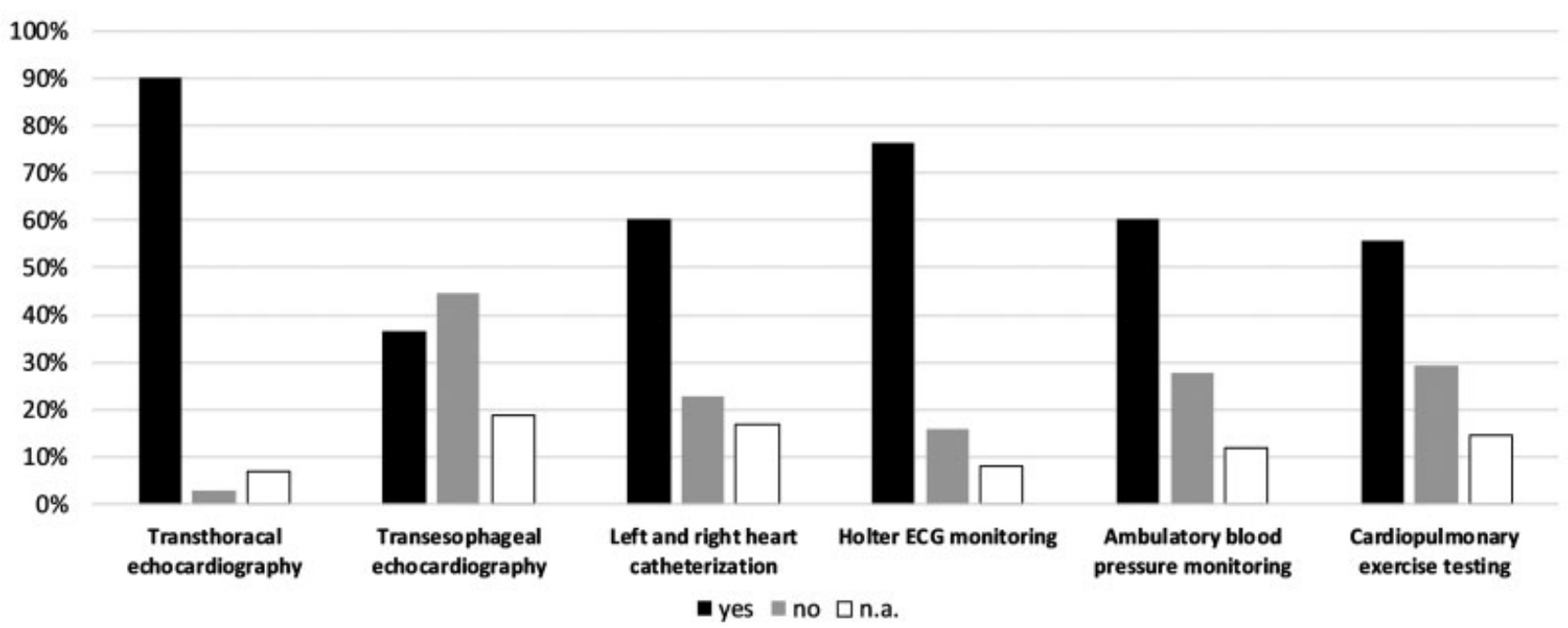

Fig. 3 Participants' opinion as to whether the required number of procedures can be achieved within 3 years of training. Percentages reflect the number of responses $(n=102)$.

exposure to congenital cardiac pathologies; this would be a great opportunity for the DGPK to provide a nation-wide standardized high-quality approach for future trainees. The 4-week PCBC leaves learners with greater sense of preparedness through a deeper foundation of knowledge which improved trainee confidence. ${ }^{3,4}$ Thereafter, general pediatric cardiology training lasting 3 years could comprise clinical rotations for 24 months (including outpatient clinic, cardiac ICU, normal ward, cardiac catheterization) and subsequent 12 months of elective training including clinical research based on fellows' interests and strengths. ${ }^{5}$ Mentoring systems by more experienced fellows or consultants would help overcome initial clinical and scientific hurdles. ${ }^{6}$ Besides a general pediatric cardiology fellowship, we would strongly support the development of subspecialty fellowship programs for fellows who have undergone general training (such as interventional cardiology, imaging, fetal cardiology, etc.).

Table 2 Interests in subspecialties of pediatric cardiology

\begin{tabular}{|l|l|l|}
\hline $\begin{array}{l}\text { Interests in subspecialties of } \\
\text { pediatric cardiology }\end{array}$ & N & $\%$ \\
\hline General pediatric cardiology & 75 & 75.0 \\
\hline Cardiac intensive care medicine & 67 & 67.0 \\
\hline Imaging (MRI, echo, CT) & 45 & 45.0 \\
\hline Interventional & 42 & 42.0 \\
\hline Research & 28 & 28.0 \\
\hline Rhythmology/electrophysiology & 19 & 19.0 \\
\hline Transplant & 19 & 19.0 \\
\hline GUCH & 13 & 13.0 \\
\hline Rehabilitation & 2 & 2.0 \\
\hline $\begin{array}{l}\text { Other (psychosocial aspects, fetal } \\
\text { echocardiography, cardiac infectiology) }\end{array}$ & 3 & 3.0 \\
\hline
\end{tabular}

Abbreviations: $\mathrm{CT}$, computed tomography; GUCH, grown-ups with congenital heart disease; MRI, magnetic resonance imaging. Note: Percentages reflect the number of responses $(n=100)$.
This would not only improve the quality of clinical work in general but it would also ensure promising perspectives for pediatric cardiologists after their basic cardiology education.

Furthermore, we identified the strong desire among fellows to participate in compassionate bedside teaching, especially regarding invasive procedures (e.g., central line on the ICU, TEE, and cardiac catheterization). As some patients may be critically ill and it is necessary to maintain patient safety, it is nevertheless extremely important to provide fellows with adequate training experience; this however requires in some cases more time but mainly more teaching commitment of consultants. This aspect should be one of the items assessed by external objective evaluations. Comparable to surgical specialties, it is hard to achieve the required numbers of certain procedures during our 3-year training at most institutions, the reasons however are mainly due to an apparent lack of consultant motivation than real medical objections. ${ }^{7}$ There are several examples of how to realize trainee education for invasive procedures: mentored simulator-based training, for example for TEE, central lines on the ICU, or cardiac catheterization. After evaluation of simulator training, fellows reported manual improvement, faster learning, and increased comfort with the procedure of the trainee. ${ }^{8-11}$ In surgical specialties, the independent execution of substeps (within the entire procedure) is done to enhance trainee motivation and help them become gradually adept at complicated procedures. ${ }^{12,13}$ This concept could also apply to complex procedures in the catheterization laboratory, whereas simple procedures such as closures of the atrial septal defect, balloon dilatation of coarctation, pulmonary stenosis, or closure of a patent ductus arteriosus could be excellent teaching procedures. As the participating fellows suggested, a positive feedback culture and regular educational sessions are essential to provide good teaching. However, as pediatric cardiology fellows in Germany appear to be generally satisfied with their training and describe motivated teaching colleagues, we assume that the recommend improvements will be rapidly incorporated within the clinical daily life. 


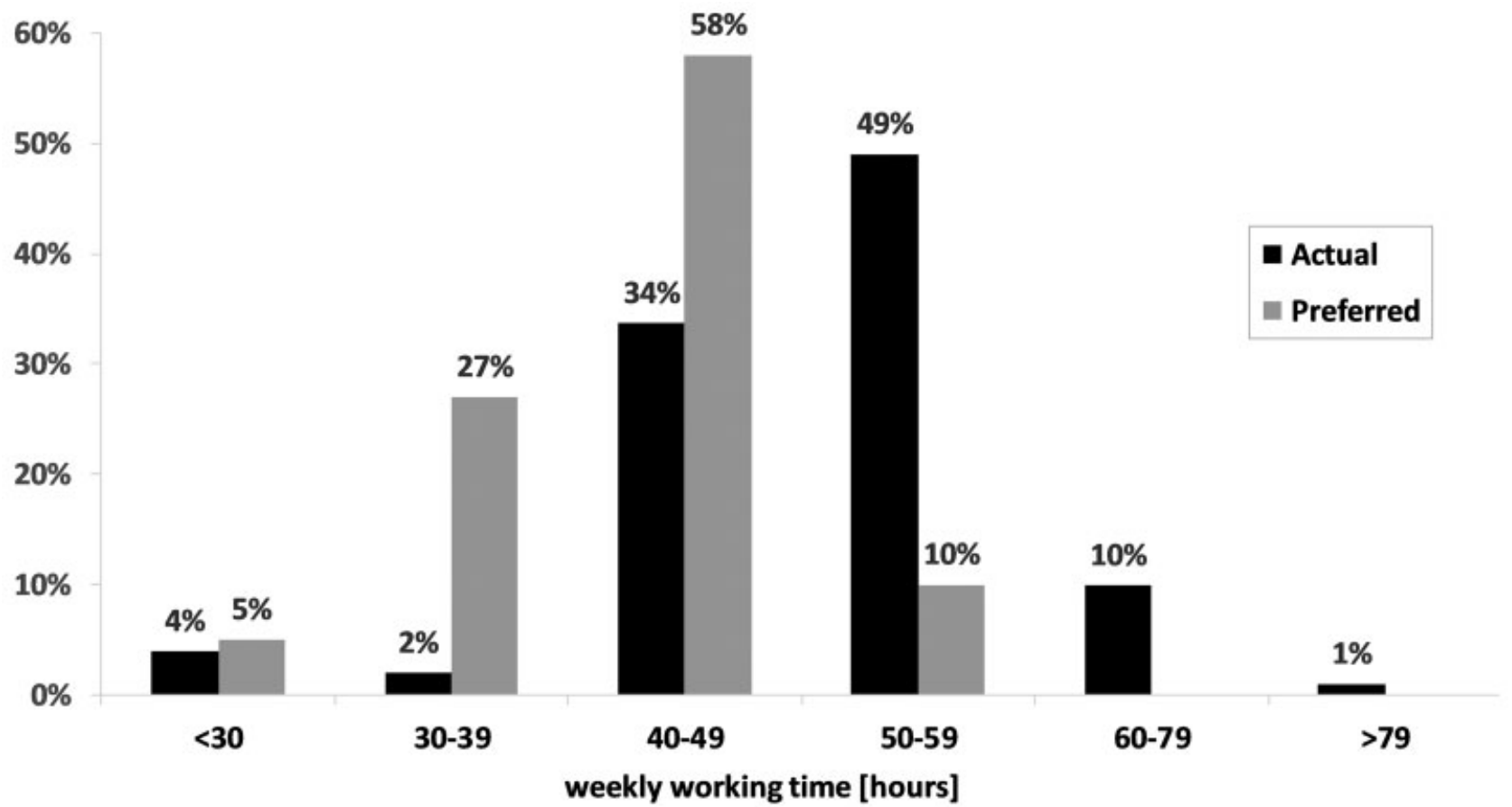

Fig. 4 Actual and preferred weekly working time (hours). Percentages reflect the number of responses (actual: $n=101 ;$ preferred: $n=100$ ).

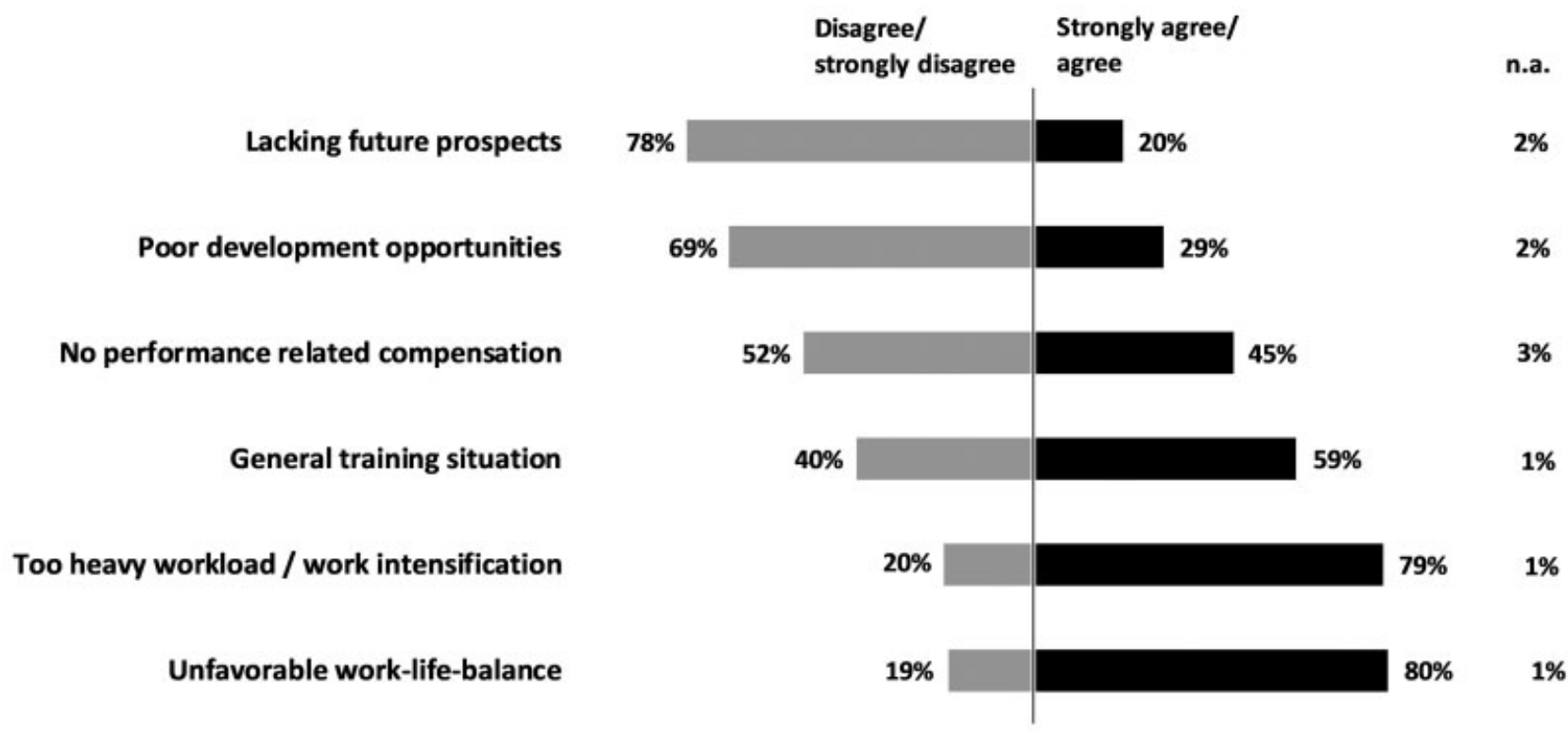

Fig. 5 Reasons for less attractiveness of fellowships in pediatric cardiology. Percentages reflect the number of responses $(n=100)$.

Research in Pediatric Cardiology and Congenital Heart Disease-The Need for Better Strategies to Improve Research Engagement

In Germany, there is a strong call for well-focused research in the field of CHD, by the DGPK, patient organizations, and directors of the departments of pediatric cardiology and pediatric cardiac surgery. ${ }^{14}$ Experience in cardiovascular research remains an essential but not mandatory component of pediatric cardiology fellowships. As most of our responding fellows are working at a university hospital, half of the fellows are involved in research projects or are following an academic career. These numbers are comparable to the percentage of fellows engaged in research reported in the survey by the "Junges Forum" of the German Society for Thoracic, Cardiac and Vascular Surgery. ${ }^{7}$ However, compared with fellowship programs in Canada and the United States, almost $>85 \%$ of all fellows reported participation in research. ${ }^{15,16}$ In our study, research is being conducted mainly outside regular working hours and not during protected research time. This might be the main reason, why the proportion of researchers among German fellows is lower. Research is an activity that takes time, involves formulating scientific questions, and taking a step back to have a look at the bigger picture. Unfortunately, structured programs 
supporting young fellows in developing research projects and guaranteeing a productive research environment barely exist in Germany. Pediatric cardiology is a specialty entailing a strong demand for clinical training and skills. However, to improve the scientific work in CHD programs, mentoring and clinical work redistribution need to be discussed to help young fellows develop research questions and interests. An early introduction to scientific work as implemented in fellowships in Canada and the United States might increase research awareness among young fellows to support academic careers. ${ }^{17,18}$

\section{How to Improve Work-Life Balance in Pediatric Cardiology-Need for More Balance}

Pediatric cardiology fellows experience an intense workload including clinical activities and research and trying to balance those demands with their personal life. An unfavorable work-life balance can lead to dissatisfaction that can impair productivity and may result in suboptimal patient care. ${ }^{19}$ The work-life balance can be measured by job satisfaction, work stress, work-family conflict, hours worked per week, career development, and training. In this survey, $80 \%$ of the fellows complained about an unfavorable work-life balance. Similar to others studies, most of the responding fellows work longer than their employment contract requires, and complain about a heavy workload and insufficient clinical training opportunities. There is a strong demand for more time for family/private life and additional staff numbers of nurses and doctors. ${ }^{20,21}$ In acknowledgment of difficulties in recruiting new and capable health care personnel, we strongly encourage all colleagues involved in staff planning to ensure optimal staffing for both physicians and nurses. Furthermore, we recommend that teaching strategies during regular working hours should be improved. Despite an unfavorable work-life balance including less predictable working hours and training opportunities, $84 \%$ of all fellows would begin a fellowship in pediatric cardiology again.

\section{Limitation}

We assume that $\sim 200$ residents/fellows are currently undergoing pediatric cardiology training in Germany. This number was generated by an online search of all pediatric cardiology clinics. Unfortunately, there are no validated numbers of residents/fellows of pediatric cardiology in Germany. Therefore, we cannot calculate the precise percentage of respondents to our survey. We would highly appreciate if the numbers of fellows in each field of medical training had to be reported to the corresponding state medical board annually.

\section{Conclusion}

This is the first national survey of residents and fellows training in pediatric cardiology in Germany. The vast majority of pediatric cardiology fellows are satisfied with their working environment and their choice of career in becoming a pediatric cardiologist. Besides the heavy workload, we identified an urgent desire for more structured clinical training, especially a reliable rotational system and better teaching of manual skills possibly evaluated by external quality control.

Conflict of Interest

The authors have no conflict of interest to declare.

\section{Acknowledgments}

We thank the advisory council of the "Junges Forum" of the DGPK especially Victoria Ziesenitz, Moritz Merbecks, Svenja Krück, and Muhannad Alkassar for contribution of the concept of the study and proofreading the manuscript. We thank Carole Cürten for language editing.

\section{References}

1 Herzstiftung D. Deutscher Herzbericht 2018;2018:165-196. Available at https://www.herzstiftung.de/herzbericht. Accessed on January 2, 2020

2 Osterloh F. Mehr personal, weniger Bürokratie. Dtsch Arztebl 2017; 27-28:1365. Available at https://www.aerzteblatt.de/archiv/ 192374/Krankenhausaerzte-Mehr-Personal-weniger-Buerokratie. Accessed on January 2, 2020

3 Allan CK, Tannous P, DeWitt E, et al. A Pediatric Cardiology Fellowship Boot Camp improves trainee confidence. Cardiol Young 2016;26(08):1514-1521

4 Ceresnak SR, Axelrod DM, Sacks LD, Motonaga KS, Johnson ER, Krawczeski CD. Advances in Pediatric Cardiology Boot Camp: Boot Camp training promotes fellowship readiness and enables retention of knowledge. Pediatr Cardiol 2017;38(03):631-640

5 Brown AE, Bradbrook KE, Casey FE. A survey of adult and pediatric cardiology fellows on training received in family planning counseling. J Womens Health (Larchmt) 2019

6 Flyer JN, Joong A. Improving peer mentorship: a novel fellow "House" program. J Am Coll Cardiol 2016;68(25):2907-2910

7 Poetini AL, Guenther SPW, Lewandowski J, et al. Residents' survey 2013 - Between requirements and reality in cardiac surgery departments in Germany. Z Herz- Thorax- Gefäßchir 2014;28: 352-362

8 Damp J, Anthony R, Davidson MA, Mendes L. Effects of transesophageal echocardiography simulator training on learning and performance in cardiovascular medicine fellows. J Am Soc Echocardiogr 2013;26(12):1450-1456.e2

9 Alsaad AA, Bhide VY, Moss JL Jr, Silvers SM, Johnson MM, Maniaci $M J$. Central line proficiency test outcomes after simulation training versus traditional training to competence. Ann Am Thorac Soc 2017;14(04):550-554

10 Bagai A, O’Brien S, Al Lawati H, et al. Mentored simulation training improves procedural skills in cardiac catheterization: a randomized, controlled pilot study. Circ Cardiovasc Interv 2012;5(05): 672-679

11 Joshi A, Wragg A. Simulator training in interventional cardiology. Interv Cardiol (Lond) 2016;11(01):70-73

12 Roeth AA, Mille M. What do young surgeons want? Modern requirements for senior surgeons [in German]. Zentralbl Chir 2018;143(01):50-54

13 Meyerson SL, Sternbach JM, Zwischenberger JB, Bender EM. Resident Autonomy in the operating room: expectations versus reality. Ann Thorac Surg 2017;104(03):1062-1068

14 Helm PC, Körten MA, Abdul-Khaliq H, et al. Three parties, one direction: Research priorities in adults with congenital heart disease. What do professionals, patients and relatives want to know? Int J Cardiol 2016;207:220-229

15 Dehghani P, Wood DA, Sharieff W, Basit N, Cheema AN. Interventional cardiology fellowship training in Canada: a report card 
e8 National Survey on Training in Pediatric Cardiology Horst et al.

using standardized criteria. Catheter Cardiovasc Interv 2011;78 (02):179-186

16 Haneef Z, Chiang S, Rutherford HC, Antony AR. A survey of neurophysiology fellows in the United States. J Clin Neurophysiol 2017;34(02):179-186

17 Brown DW, Allan CK, Newburger JW. Training fellows in paediatric cardiology: the Harvard experience. Cardiol Young 2016;26 (08):1499-1506

18 Moodie D. Pediatric cardiology fellow education - two important components. Congenit Heart Dis 2016;11(02):101
19 Dasgupta S, Dave I, McCracken CE, Mohl L, Sachdeva R, Border W. Burnout and work life balance among pediatric cardiologists: A single center experience. Congenit Heart Dis 2019;14(03): 350-355

20 Saini A. Work-life balance: keep the cycle moving - find a purpose, set priorities, and manage time well then reassess and reset. Front Pediatr 2016;3:118

21 MB-Monitor (2017). Available at: www.marburger-bund.de/sites/default/files/files/2018-09/gesamtauswertung-mbmonitor-2017-presse-pk-website.pdf. Accessed May 27, 2017 